\title{
Air Quality Status in Wuhan City during and One Year after the COVID-19 Lockdown
}

\section{Aerosol and Air Quality Research}

Special Issue:

Special Issue on Air Quality in a Changed World: Regional, Ambient, and Indoor Air Concentrations from the COVID to Post-COVID Era (II)

\section{OPEN ACCESS}

Received: October 15, 2021

Revised: December 6, 2021

Accepted: December 6, 2021

\section{${ }^{*}$ Corresponding Author: \\ yuyan@mail.xjtu.edu.cn}

\section{Publisher:}

Taiwan Association for Aerosol Research

ISSN: $1680-8584$ print

ISSN: 2071-1409 online

\section{Copyright: The Author(s).} This is an open access article distributed under the terms of the Creative Commons Attribution License (CC BY 4.0), which permits unrestricted use, distribution, and reproduction in any medium, provided the original author and source are cited.

\section{Crystal Jane Ethan, Kingsley Katleho Mokoena, Yan Yu*}

School of Public Health, Xi'an Jiaotong University, Health Science Center, Xi'an, Shaanxi 710061, China

\section{ABSTRACT}

Anthropogenic activities have been established to have severe adverse effects on air quality. Consequently, the nature of daily events, directly and indirectly, influences the nature of air pollution observed. This study focused on describing air quality one year after the Coronavirus (COVID-19) pandemic lockdown (since anthropogenic activities had resumed back to normal) in Wuhan.

Using the independent t-test, the means of air quality index (AQI) and individual air pollutants concentration during the lockdown were compared with the means after the lockdown. Cohen's $\mathrm{d}$ was estimated to quantify the standardized mean difference observed.

Based on the average AQI, the air quality in Wuhan during and after the lockdown was rated "good"; and ranged between 59.7 and 99.8. Indicators of traffic pollution, particularly $\mathrm{NO}_{2}$, were significantly higher after the lockdown; noting a $162 \%$ increment in concentration. A $36 \%$ increase was also noted for ozone immediately after the lockdown; while a 33\% increase was noted for $\mathrm{SO}_{2}$ roughly eight months post lockdown. At different periods post lockdown, particulate matter pollution varied, with some time-spans observing lower concentrations and others higher concentrations than the lockdown. A trade-off effect between $\mathrm{PM}_{2.5}$ and $\mathrm{O}_{3}$ was also noted during and after the lockdown.

One year post the lockdown, air quality in Wuhan has observed some drastic changes. Hence, there is a need for more studies to identify other specific and peculiar sources of emissions in the city. Relevant findings should be employed in supporting the implementation of stringent emission control.

Keywords: Air pollution, COVID-19, Particulate matter, Traffic pollution, Air quality

\section{INTRODUCTION}

In recent decades, the People's Republic of China has transformed from being the traditional agricultural state to being the world's second-leading economy. Behind that shift, drastic industrial development, urbanization, and political changes have been the leading driving forces post-1949. Today, China is considered to be the world's leading and largest manufacturing powerhouse, accounting for approximately $50 \%$ of all industrial goods in the world (Wen, 2016). In as much as industrial development generally improved the quality of life for the Chinese people, contributed to the economic development of the region, and brought exponential economic growth to the country (while also benefiting countries that get industrial supplies from China) in the last few decades, the quality of air and the environment has been affected negatively.

For many years, the level of air pollution has been associated with several adverse health effects and is among the leading causes of death globally (Mokoena et al., 2020). In China, air pollution has been reported to be a serious health threat that often leads to death by various authors (Ethan et al., 2020; Yin et al., 2020). Moreover, air pollution levels have been observed to be affected by anthropogenic activities such as major events (Wang et al., 2020). The outbreak of COVID-19 in late December 2019 rapidly affected many cities globally, including Wuhan. In an 
attempt to curtail the spread of the virus, a city-wide lockdown (restriction of movement) was imposed in Wuhan on January 23, 2020, and lasted until April 8, 2020. Although the lockdown restrictions were meant to protect the public and prevent the further spread of the ravaging virus, they also had an impact on the global population. These restrictions had major effects from many fronts and led to less social interactions, closure of workplaces (including manufacturing industries), lesser vehicles on roads (and related emissions), inflated food prices, increased domestic violence cases, challenges in education (particularly in areas with lack of internet infrastructure), inflated healthcare prices, and a deceleration in the global economics, among many other effects. After this global development and response to COVID-19, the global quality of air was widely reported to have improved due to reduced emissions and due to more than 140 countries being on lockdown (Chan et al., 2020; Ethan et al., 2021).

Therefore, the current study aims to describe air quality and key air pollutants concentration level during the COVID-19 lockdown (January 23, 2020-April 8, 2020) and one year post the lockdown (April 9, 2020-April 8, 2021) in Wuhan; revealing changes in air quality post lockdown. The study hypothesizes that there was no increase in air pollution after the COVID-19 lockdown.

\section{MATERIALS AND METHODS}

Air quality index and concentration levels for criteria air pollutants were collected for Wuhan city, the epicenter of the outbreak in China. The data covered the precise period of the COVID-19 lockdown (January 23, 2020-April 8, 2020) as well as one year post the lockdown (April 9, 2020April 8,2021$)$. Statistical analysis was done using the Independent samples $t$-test.

\subsection{Study Area}

The study area, Wuhan, is the capital of Hubei province and is the most populous city in central China with an estimated population of over 11 million residents (Chen et al., 2021). It is located at the confluence of the Yangtze and the Han River (Fig. 1). The city observes four seasons i.e., spring, summer, autumn, and winter. Its main sources of air pollution include coal combustion for

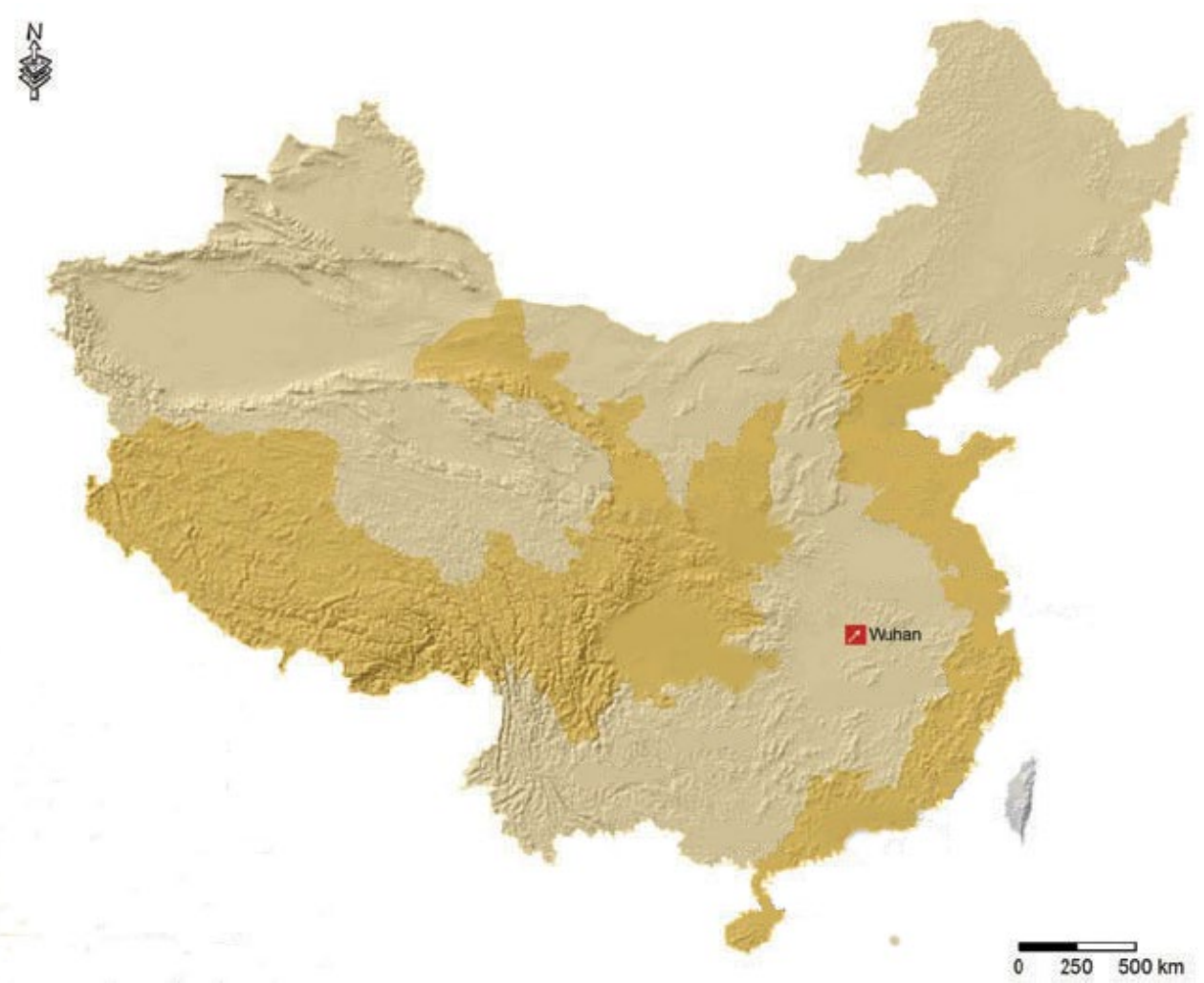

Fig. 1. Map of China showing the study area (Wuhan city). 
heating, combustion of fossil fuels from vehicles, and industrial fumes. As the first city to implement a lockdown; Wuhan observed the closure of offices, manufacturing industries, educational institutions, commercial centers, leisure places, etc. for 76 days.

\subsection{Data}

Daily records for Air quality index - AQI, fine particulate matter - $\mathrm{PM}_{2.5}\left(\mu \mathrm{g} \mathrm{m}^{-3}\right)$, coarse particulate matter - $\mathrm{PM}_{10}\left(\mu \mathrm{g} \mathrm{m}^{-3}\right)$, ozone $-\mathrm{O}_{3}\left(\mu \mathrm{g} \mathrm{m}^{-3}\right)$, Sulfur dioxide $-\mathrm{SO}_{2}\left(\mu \mathrm{g} \mathrm{m}{ }^{-3}\right)$, Nitrogen dioxide - $\mathrm{NO}_{2}\left(\mu \mathrm{g} \mathrm{m}^{-3}\right)$ and Carbon monoxide - $\mathrm{CO}\left(\mathrm{mg} \mathrm{m}^{-3}\right)$ were collected from AQI China - a national online database. The data of interest cover from January 23, 2020 to April 8, 2020 (the lockdown period in Wuhan). In addition, similar data were collected for the succeeding 365 days (April 9, 2020-April 8, 2021). All data were generated from environmental monitoring stations within the city. No dates were missing. Note: all air pollutants were measured in microgram per cubic meter $\left(\mu \mathrm{g} \mathrm{m}^{-3}\right)$ except $\mathrm{CO}$, which was measured in milligram per cubic meter $\left(\mathrm{mg} \mathrm{m}^{-3}\right)$.

\subsection{Statistical Analysis}

The main statistical test employed was the Independent samples $t$-test.

\subsubsection{Phase 1: Data Categorization}

To group the data into reasonable categories, the length of the lockdown (76 days) was used as a determining factor to fit ranges for each category. This was to avoid any issue of robustness or statistical power as a result of extreme differences in sample size (The Analysis Factor, 2021). The entire data retrieved from January 23, 2020 to April 9, 2021, was divided into six categories as follows:

Category K: COVID-19 lockdown period (January 23, 2020-April 8, 2020)

Category A: 1-76 days post lockdown (April 9, 2020-June 23, 2020)

Category B: 77-152 days post lockdown (June 24, 2020-September 7, 2020)

Category C: 153-228 days post lockdown (September 8, 2020-November 22, 2020)

Category D: 229-289 days post lockdown (November 23, 2020-January 22, 2021)

Category E: 290-365 days post lockdown (January 23, 2021-April 8, 2021)

\subsubsection{Phase 2: Descriptive analysis}

The descriptive analysis summarizes the data. It is broadly spread into two major classes, i.e. (i) measure of central tendency (mean and median) and (ii) measure of variability (standard deviation, percentile, and ranges) (Pérez-Vicente and Expósito-Ruiz, 2009).

\subsubsection{Independent t-test analysis}

The independent t-test, commonly known as the two-sample t-test, is an inferential statistical technique that assesses if two distinct groups have statistically significant differences in their means (Landau and Everitt, 2004). The dependent variable must have a normal distribution to perform a $t$-test. The data utilized in the study satisfied the assumption of normality in this aspect, since the data's size was sufficient i.e., ( $n=76$ for all categories except for Category $D, n$ =61). According to Piovesana and Senior (2016), a sample size of 50 is adequate for normalcy. As a result, the sample size of data used in this study was sufficient to ensure normalcy. Furthermore, the independent variables must be unrelated to one another. This condition was satisfied since the concentration of air pollution on lockdown days and post lockdown days are completely unrelated (different dates). The following comparisons were employed in the analysis: Category $A$ vs. Category K; Category B vs. Category K; Category C vs. Category K; Category D vs. Category K and Category $\mathrm{E}$ vs. Category K. The mean difference was estimated as follows: post lockdown (Category A-E) - lockdown period (Category K). The $t$-score and $p$-value were also generated from the test. Statistical analysis was carried out using IBM SPSS 24.0 (IBM, Armonk, NY, USA).

\subsubsection{Phase 4: Estimation of effect size}

For additional guarantee that the differences noted by the $t$-test are credible, the effect size (i.e., the standardized difference between two means) was calculated using Cohen's d (Eq. (1)) (Cohen, 1998). 
Cohen's d is given as:

$d=M 1-M 2 /$ spooled

where $M_{1}$ and $M_{2}$ are the means for groups 1 and 2, and $S_{\text {pooled }}$ is the pooled standard deviation for both groups. The Rstats effect size calculator was used to calculate Cohen's d (Rstat, 2012). To estimate the actual effect, 1 Cohen's $d=1 \mathrm{~S}$ (standard deviation); $1 \mathrm{~S}=1 \mathrm{z}$-score; and $1 \mathrm{z}$-score $=$ a specified value on the $z$-score table. The defined value of the $z$-scores was ascertained using Rstats' normal distribution table. In reality, the final number (mean z) reveals by how many points one group's mean is lower or greater than the other (Dulark, 2009). The rule of thumb for Cohen's $d$ interpretation is as follows: Cohen and Sawilowsky's convention for effect size $(d \leq 0.01$ - very small; $d=0.01-0.2$ - small; $d=0.2-0.5$ - medium; $d=0.5-0.8$ - large; $d=0.8-1.2$ - very large; $d=$ 1.2-2 - huge) equate effect sizes to the amount of actual difference between two groups (Sawilowsky, 2009).

\subsubsection{Phase 5: Interactive visualization of effect size}

To visually display the mean difference and Cohen's d, Magnusson's visualization tool was employed; utilizing the means and standard deviations of both groups. The graph estimates and reveals the percentage of Non-overlap (Cohen's $U_{3}$ ), Overlap, and Probability of superiority between two groups. Cohen's $U_{3}$ shows the percentage of group $A$ that is above the estimated average of group B. The Overlap reveals the percentage of groups A and B that are similar. While, the Probability of superiority indicates the possibility that a randomly selected entry from group A will be higher than a randomly selected entry from group B (Magnusson, 2014).

\section{RESULTS}

\subsection{Descriptive Statistics}

Table 1 shows some vital features of air quality and air pollutants' concentration during and one year after the lockdown. The average AQI during these periods ranged from 59.7 (lockdown) to 99.8 (229-289 days post lockdown - Category D), indicating the least and highest average scores respectively. The lockdown period also maintained the least daily AQI of 20, while the highest daily AQI, 233, was recorded also for Category D. Similar to AQI, the least daily and least average $\mathrm{NO}_{2}$ concentration was recorded during the lockdown, with $10 \mu \mathrm{g} \mathrm{m}^{-3}$ and $22.4 \mu \mathrm{g} \mathrm{m}^{-3}$ respectively; while Category $D$ still recorded the highest daily $\left(58.7 \mu \mathrm{g} \mathrm{m}^{-3}\right)$ and highest average $\left(124 \mu \mathrm{g} \mathrm{m}^{-3}\right) \mathrm{NO}_{2}$ concentration. For particulates, the least average concentration was recorded 77-152 days post lockdown with $21.9 \mu \mathrm{g} \mathrm{m}{ }^{-3}$ for $\mathrm{PM}_{2.5}$ and $38.3 \mu \mathrm{g} \mathrm{m}^{-3}$ for $\mathrm{PM}_{10}$. $\mathrm{SO}_{2}$ also recorded its least concentration $\left(6.3 \mu \mathrm{g} \mathrm{m}^{-3}\right) 77-152$ days post lockdown. In contrast to other air pollutants, $\mathrm{O}_{3}$ noted its least concentration $\left(45.4 \mu \mathrm{g} \mathrm{m}^{-3}\right)$ 229-289 days post lockdown, and its highest concentration (117.9 $\mu \mathrm{g} \mathrm{m}^{-3}$ ) 77-152 days post lockdown. CO also observed its least concentration $\left(0.6 \mathrm{mg} \mathrm{m}^{-3}\right.$ ) at a different time (290-365 days post lockdown).

\subsection{Graphical Presentation of AQI and Key Air Pollutants Concentration Level}

Fig. 2 graphically displays some characteristic features of AQI and individual air pollutants concentration during and post lockdown. For each air pollutant, the graph reveals the presence of outliers during one or more period(s); indicating days of extreme pollution existed during those periods. Additionally, $\mathrm{CO}$ and $\mathrm{O}_{3}$ noted some outliers which also indicated a drastic reduction in concentration during the lockdown and 1-76 days post lockdown respectively. However, for $\mathrm{SO}_{2}$ every period from the lockdown to one year after observed bouts of extreme pollution; as seen with the presence of outliers. Regarding particulates, $\mathrm{PM}_{2.5}$ recorded more days of extreme pollution than $\mathrm{PM}_{10}$ during and after the lockdown.

Based on average AQI and average air pollutants concentration level, Fig. 3 graphically displays the level of air pollution in Wuhan during and one year post the COVID-19 lockdown. The pattern for $A Q I$ and all air pollutants except ozone was slightly similar for the entire period (lockdown to 290-365 dpl). Precisely, AQI and $\mathrm{NO}_{2}$ observed the lowest concentration levels during the lockdown, followed by a slight increase 1-76 days post lockdown, a decrease between $77-228$ days post 
Table 1. Descriptive statistics for air quality index and air pollutant concentration in Wuhan during and post the COVID-19 lockdown.

\begin{tabular}{|c|c|c|c|c|c|c|c|c|}
\hline Time-span & Mean (SD) & Median & Min & Max & IQR & Range & $\mathrm{P} 25$ & P75 \\
\hline \multicolumn{9}{|l|}{ Air Quality Index } \\
\hline Lockdown & $59.7(21.6)$ & 60 & 20 & 128 & 34 & 108 & 41 & 75 \\
\hline $1-76 \mathrm{dpl}$ & 70.2 (21.9) & 70 & 30 & 127 & 32 & 97 & 51 & 83 \\
\hline 77-152 dpl & 69.5 (29.6) & 61.5 & 28 & 133 & 49 & 105 & 44 & 93 \\
\hline $153-228 \mathrm{dpl}$ & 70.5 (24.4) & 74 & 24 & 150 & 39 & 126 & 49 & 88 \\
\hline 229-289 dpl & 99.8 (41.5) & 95 & 33 & 223 & 46 & 190 & 74 & 120 \\
\hline 290-365 dpl & $71.2(26.7)$ & 72 & 26 & 159 & 29 & 133 & 53 & 83 \\
\hline \multicolumn{9}{|c|}{ Fine Particulate Matter $\left(\mathrm{PM}_{2.5} \mu \mathrm{g} \mathrm{m}^{-3}\right)$} \\
\hline Lockdown & 38.5 (17.5) & 37 & 8 & 97 & 20 & 89 & 27 & 47 \\
\hline $1-76 \mathrm{dpl}$ & 29.4 (10.7) & 29 & 9 & 55 & 15 & 46 & 21 & 36 \\
\hline $77-152 \mathrm{dpl}$ & $21.9(9.2)$ & 22 & 7 & 53 & 14 & 46 & 14 & 28 \\
\hline $153-228 \mathrm{dpl}$ & 34.9 (13.1) & 37 & 5 & 58 & 20 & 53 & 25 & 45 \\
\hline $229-289 \mathrm{dpl}$ & $70.1(36.0)$ & 64 & 16 & 173 & 46 & 157 & 45 & 91 \\
\hline $290-365 \mathrm{dpl}$ & $46.3(21.9)$ & 41 & 11 & 121 & 27 & 110 & 35 & 58 \\
\hline \multicolumn{9}{|c|}{ Course Particulate Matter $\left(\mathrm{PM}_{10} \mu \mathrm{g} \mathrm{m}^{-3}\right)$} \\
\hline Lockdown & $52.2(22.0)$ & 52 & 12 & 103 & 36 & 91 & 34 & 70 \\
\hline $1-76 \mathrm{dpl}$ & $51.8(21.6)$ & 51 & 12 & 104 & 31 & 92 & 35 & 66 \\
\hline $77-152 \mathrm{dpl}$ & $38.3(15.5)$ & 38 & 9 & 67 & 58 & 28 & 25 & 53 \\
\hline $153-228 \mathrm{dpl}$ & $64.1(29.4)$ & 65 & 9 & 141 & 46 & 132 & 40 & 86 \\
\hline $229-289 \mathrm{dpl}$ & $99.5(42.3)$ & 96 & 18 & 216 & 49 & 198 & 81 & 129 \\
\hline $290-365 \mathrm{dpl}$ & 71.6 (34.9) & 70 & 16 & 177 & 45 & 161 & 46 & 93 \\
\hline \multicolumn{9}{|c|}{ Nitrogen dioxide $\left(\mathrm{NO}_{2} \mu \mathrm{g} \mathrm{m}^{-3}\right)$} \\
\hline Lockdown & $22.4(7.7)$ & 22 & 10 & 54 & 9 & 44 & 17 & 26 \\
\hline $1-76 \mathrm{dpl}$ & $33.2(11.3)$ & 30 & 14 & 65 & 18 & 51 & 24 & 42 \\
\hline 77-152 dpl & $27.3(7.2)$ & 27 & 17 & 50 & 10 & 33 & 21 & 31 \\
\hline $153-228 \mathrm{dpl}$ & $48.0(19.6)$ & 42 & 19 & 88 & 32 & 69 & 32 & 64 \\
\hline $229-289 \mathrm{dpl}$ & $58.7(23.1)$ & 54 & 24 & 124 & 31 & 100 & 41 & 72 \\
\hline $290-365 \mathrm{dpl}$ & $39.9(19.2)$ & 38 & 18 & 72 & 22 & 54 & 28 & 51 \\
\hline \multicolumn{9}{|c|}{ Sulphur dioxide $\left(\mathrm{SO}_{2} \mu \mathrm{g} \mathrm{m}^{-3}\right)$} \\
\hline Lockdown & $8.1(2.8)$ & 8 & 5 & 17 & 4 & 12 & 6 & 10 \\
\hline $1-76 \mathrm{dpl}$ & $7.7(2.8)$ & 7 & 4 & 17 & 4 & 13 & 5 & 9 \\
\hline $77-152 \mathrm{dpl}$ & $6.3(1.4)$ & 6 & 4 & 11 & 2 & 7 & 5 & 7 \\
\hline $153-228 \mathrm{dpl}$ & $8.5(3.3)$ & 8 & 5 & 18 & 4 & 13 & 6 & 10 \\
\hline $229-289 \mathrm{dpl}$ & $10.8(4.1)$ & 10 & 5 & 21 & 6 & 16 & 8 & 14 \\
\hline $290-365 \mathrm{dpl}$ & $7.9(2.5)$ & 7 & 5 & 17 & 3 & 12 & 6 & 9 \\
\hline \multicolumn{9}{|c|}{ Ozone $\left(\mathrm{O}_{3} \mu \mathrm{g} \mathrm{m}^{-3}\right)$} \\
\hline Lockdown & $86.0(27.1)$ & 85 & 39 & 157 & 40 & 118 & 64 & 104 \\
\hline $1-76 \mathrm{dpl}$ & 117.1 (33.9) & 122 & 25 & 189 & 46 & 164 & 93 & 139 \\
\hline $77-152 \mathrm{dpl}$ & 117.9 (41.3) & 114 & 39 & 196 & 64 & 157 & 87 & 150 \\
\hline $153-228 \mathrm{dpl}$ & $90.5(37.1)$ & 86 & 30 & 215 & 47 & 185 & 69 & 116 \\
\hline $229-289 \mathrm{dpl}$ & $45.4(20.5)$ & 48 & 7 & 93 & 34 & 86 & 27 & 61 \\
\hline 290-365 dpl & $67.9(28.5)$ & 66 & 8 & 129 & 46 & 121 & 44 & 90 \\
\hline \multicolumn{9}{|c|}{ Carbon monoxide $\left(\mathrm{CO} \mathrm{mg} \mathrm{m}^{-3}\right)$} \\
\hline Lockdown & $0.9(0.2)$ & 0.9 & 0.5 & 1.4 & 0.2 & 0.9 & 0.8 & 1.0 \\
\hline $1-76 \mathrm{dpl}$ & $0.7(0.2)$ & 0.8 & 0.5 & 1.3 & 0.2 & 0.8 & 0.7 & 0.9 \\
\hline $77-152 \mathrm{dpl}$ & $0.7(0.2)$ & 0.8 & 0.4 & 1.2 & 0.3 & 0.8 & 0.6 & 0.9 \\
\hline $153-228 \mathrm{dpl}$ & $0.9(0.1)$ & 0.9 & 0.6 & 1.2 & 0.2 & 0.6 & 0.8 & 1.0 \\
\hline $229-289 \mathrm{dpl}$ & $1.0(0.3)$ & 1.0 & 0.5 & 1.8 & 0.5 & 1.3 & 0.7 & 1.2 \\
\hline $290-365 \mathrm{dpl}$ & $0.6(0.2)$ & 0.8 & 0.5 & 1.4 & 0.3 & 0.9 & 0.7 & 1.0 \\
\hline
\end{tabular}

dpl - days post lockdown. 

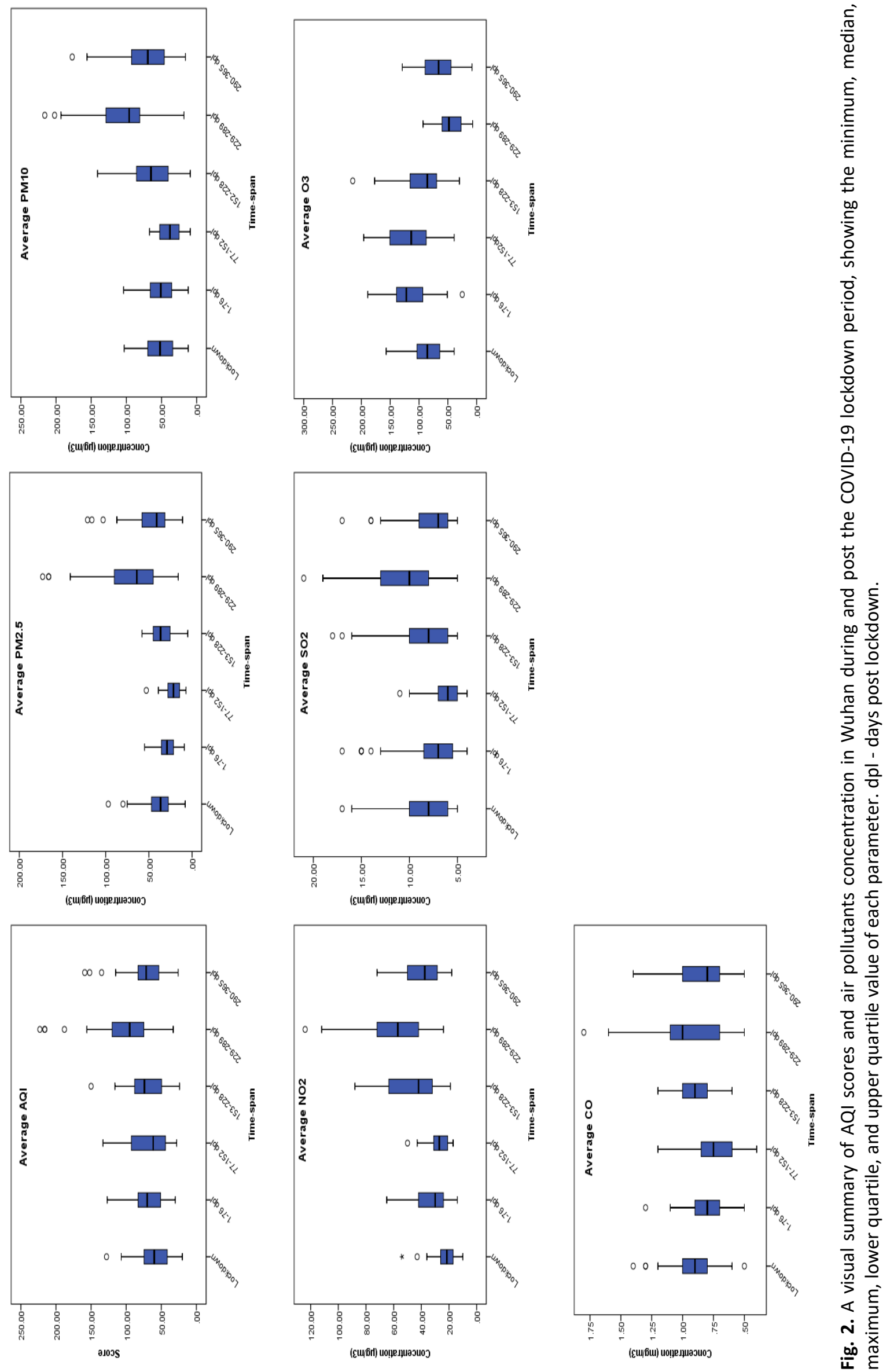

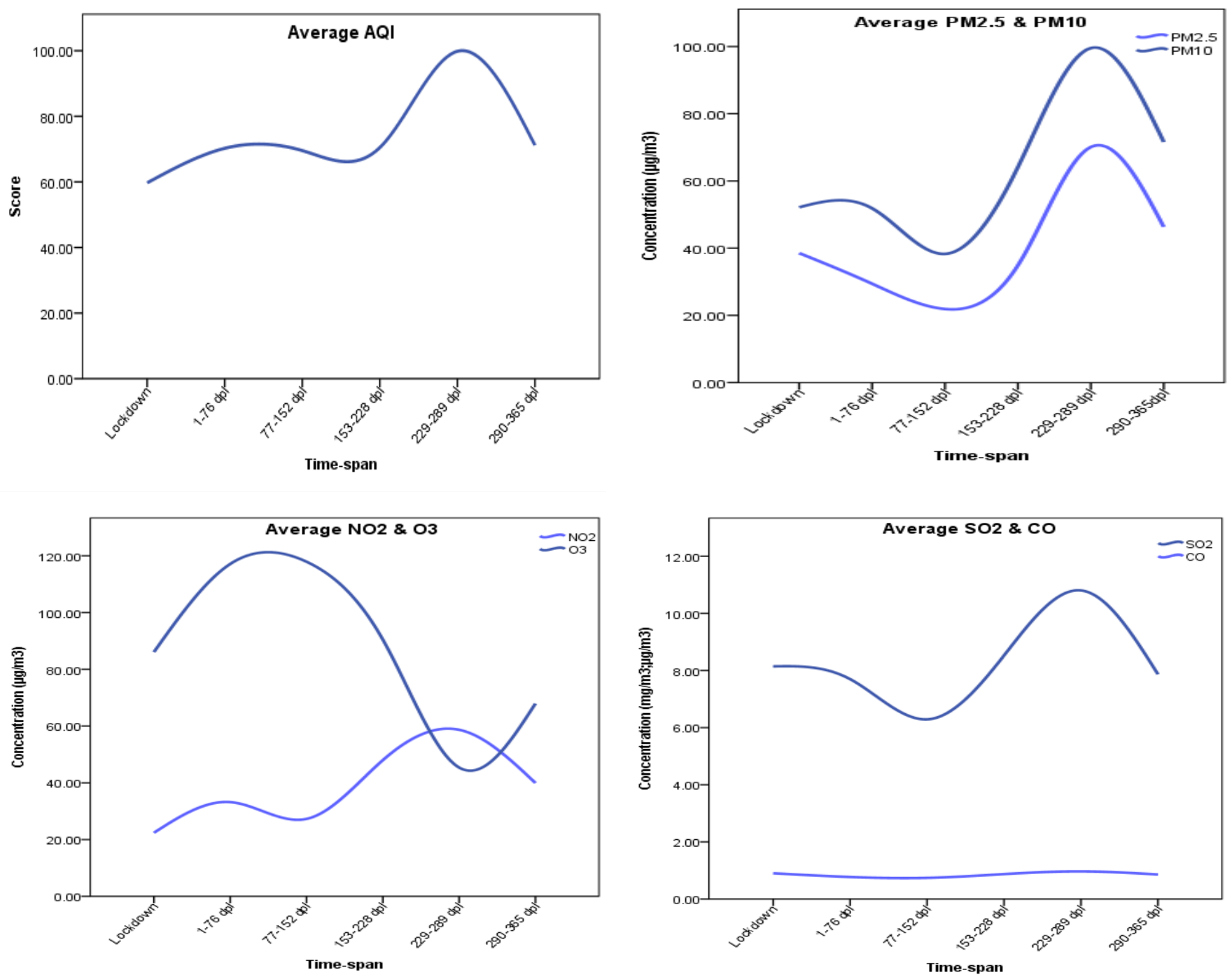

Fig. 3. Graphical display of air pollution level in Wuhan during and post the COVID-19 lockdown period, highlighting the difference in air quality at different periods. dpl - days post lockdown.

lockdown, a very sharp increase 229-289 days post lockdown and a final decrease 290-365 days post lockdown. A similar pattern was noted for $\mathrm{SO}_{2}$ and both particulates; however, in these instances, the lockdown period did not observe the lowest concentration level. A keen comparison of matching months, i.e., the lockdown period (January 23-April 8, 2020) and 290-365 dpl (January 23-April 8, 2021) reveals that concentration levels of all air pollutants except ozone were lower during the lockdown, and noticeably increased afterward. This implies that the lockdown to a great extent curtailed the emission of air pollutants; however, the resumption of regular anthropogenic activities (post lockdown) has led to an increase in emission. As previously stated, ozone showed a different pattern from other air pollutants. A moderately high concentration level was noted during the lockdown, followed by a steep increase from 1-152 days post lockdown, a gradual decrease between 153-228 days post lockdown, a steep decrease of 229-289 days post lockdown, and a final increase 290-365 days post lockdown. In the case of ozone, observation of matching months reveals higher emissions during the lockdown period.

\subsection{Description of Air Quality}

Based on the average AQI estimated, air quality in Wuhan during and after the lockdown was labeled according to the standard AQI range (China's and WHO air quality guidelines), i.e., excellent: 0-50, good: 51-100, light pollution: $101-150$, moderate pollution: $150-200$, heavy pollution: 
201-300, severe pollution: 300 >; while individual air pollutants were described based on China's 24 hours average for key air pollutants (World Air Quality Project Team, 2021). The corresponding descriptions for $\mathrm{AQI}$ and air pollutant concentration averages are given in Table 2. Overall, air quality was labeled good, during and after the lockdown. However, for individual air pollutants, particulate matter, especially $\mathrm{PM}_{10}$ observed light pollution throughout. While gaseous pollutants were mostly rated good during the lockdown and lightly polluted as time passed after the lockdown.

\subsection{Independent $t$-test Result}

Table 3 shows the estimated mean difference and its $95 \% \mathrm{Cl}, t$-test score, and effect size for comparison of air pollution averages during and after the lockdown. Statistically significant differences were observed for overall air quality and individual air pollutants during and after the lockdown; although, these differences were not noted in every category analyzed. Hence, we reject the null hypothesis. A positive difference noted for any comparison suggests that air pollution concentration was low during the lockdown and increased afterward. On the other hand, negative difference indicates air pollution during the lockdown was high and decreased afterward. Overall air quality was significantly different, i.e., better during the lockdown in comparison to air quality between 77 to 152 days post lockdown and 229 to 289 days post lockdown. Furthermore, a comparison of matching periods (i.e., the lockdown and Category E) reveals a positive but not statistically significant difference. Of all air pollutants, $\mathrm{NO}_{2}$ observed a statistically significantly lower concentration during the lockdown when compared with all categories except for Category $\mathrm{B}$; indicating a significant increase in $\mathrm{NO}_{2}$ concentration after the lockdown. For particulate pollution, $\mathrm{PM}_{10}$ noted significantly lower concentrations in more comparisons than $\mathrm{PM}_{2.5} ; \mathrm{PM}_{2.5}$ only observed a lower concentration during the lockdown when compared with Category D (229-289 days post lockdown).

\subsection{Visualization of Effect Size}

Fig. 4 graphically displays Cohen's d, mean difference, distribution of the lockdown records (indicated by the red shade), distribution of the post lockdown records (indicated by the blue shade), percentage of non-overlap records (Cohen's $U_{3}$ ), percentage of overlap records (indicated by the black shade), as well as the probability of superiority for randomly selected entries of AQI during and after the lockdown. (Note: Cohen's d displayed in this graph is the standardized mean difference estimated using Eq. (1) - see Section 2.3.4; which in turn was used to estimate the actual effect size given in Table 3. It also differs slightly from the Cohen's d derived using the RStat effect size calculator by $\pm 0.02-0.05$. From the graph below, two plots ( $B$ vs. $K$ and $D$ vs. $K$ ) are of importance, since their estimates were the least and highest mean difference respectively, and the only statistically significant outcomes as well. The largest mean difference noted in $D$ vs. K (lockdown vs. 229-289 days post lockdown) consequently resulted in the highest non-overlap (Cohen's $\mathrm{U}_{3}$ ) and probability of superiority percentages and the least overlap percentage. Cohen's $\mathrm{U}_{3}$ indicates that $83.1 \%$ of the daily AQI between November 23, 2020 to January 22, 2021 (Category D) was above the average AQI of the lockdown period (January 23, 2020-April 8, 2020).

Table 2. Air quality in 10 mega-cities during the COVID-19 outbreak, prior to the outbreak, and at a similar time in the previous year (based on average AQI score).

\begin{tabular}{|c|c|c|c|c|c|c|}
\hline \multirow{2}{*}{$\begin{array}{l}\text { Time-span } \\
\text { Air pollutant }\end{array}$} & \multicolumn{2}{|c|}{ Lockdown period } & \multicolumn{2}{|c|}{$1-76 \mathrm{dpl}$} & \multicolumn{2}{|c|}{$290-365 \mathrm{dpl}$} \\
\hline & Means & Description & Means & Description & Means & Description \\
\hline AQI & 59.7 & Good & 70.2 & Good & 71.2 & Good \\
\hline $\mathrm{PM}_{2.5}$ & 38.5 & Light pollution & 29.4 & Good & 46.3 & Light pollution \\
\hline $\mathrm{PM}_{10}$ & 52.2 & Light pollution & 51.8 & Light pollution & 71.6 & Light pollution \\
\hline $\mathrm{NO}_{2}$ & 22.4 & Good & 33.2 & Good & 39.9 & Light pollution \\
\hline $\mathrm{SO}_{2}$ & 8.1 & Good & 7.7 & Good & 7.9 & Good \\
\hline $\mathrm{O}_{3}$ & 86.0 & Good & 117.1 & Light pollution & 67.9 & Good \\
\hline $\mathrm{CO}$ & 0.9 & Good & Good & Good & 0.6 & Good \\
\hline
\end{tabular}

$\mathrm{dpl}$ - days post lockdown. Six ratings of air quality: Excellent: 0-50, Good: 51-100, Light pollution: 101-150, Moderate pollution: 150-200, Heavy pollution: 201-300, Severe pollution: 300>. 


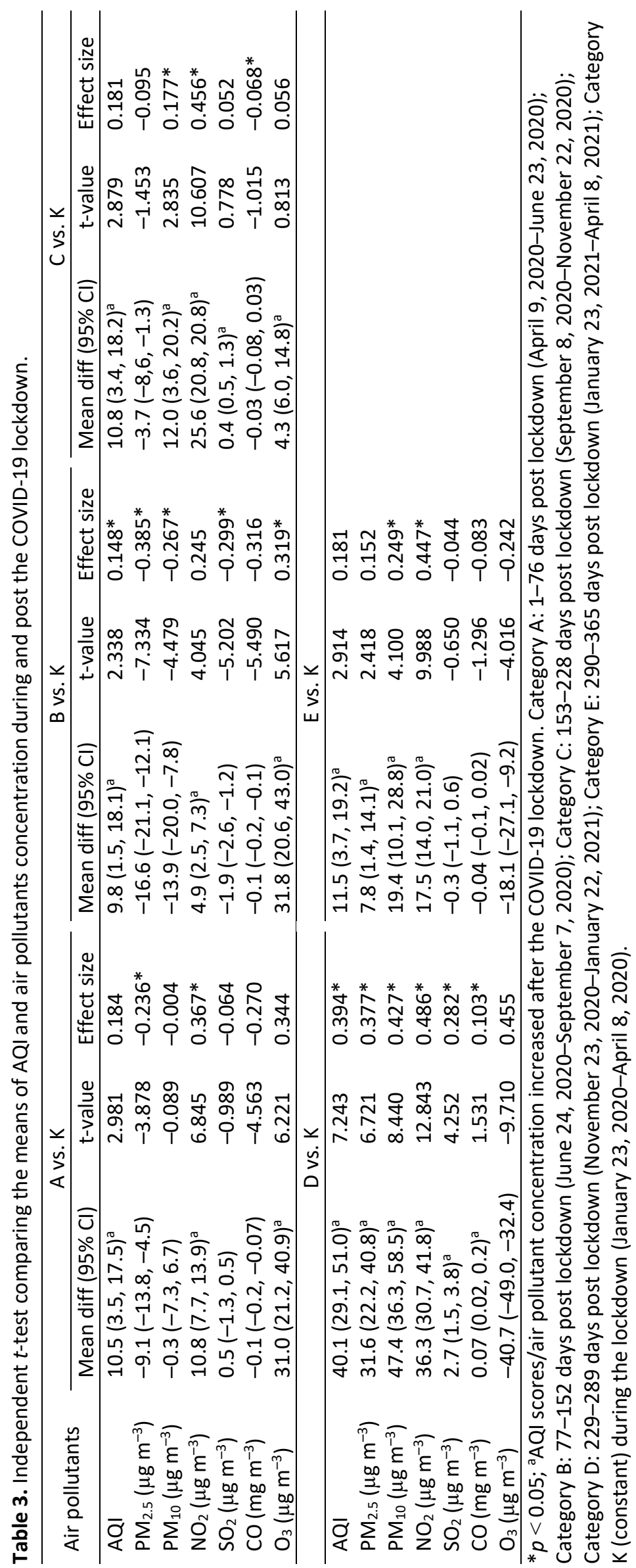



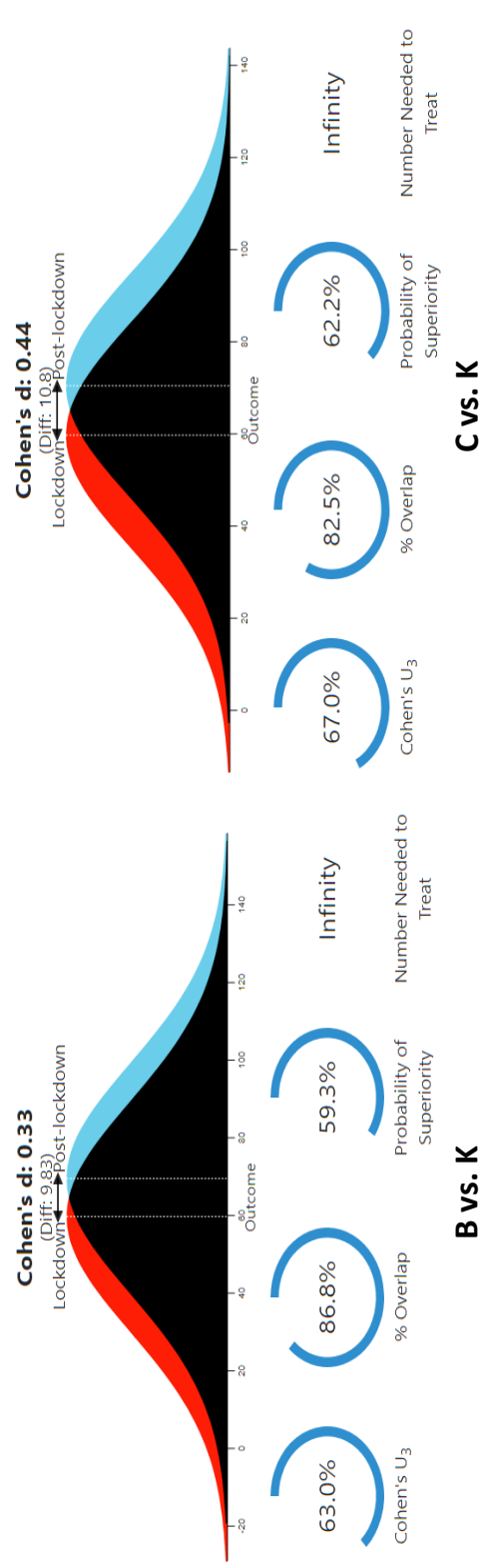

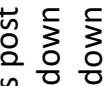

帘 능 흥

获落

荙茎学

品 $\infty$

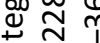

نำ

茓

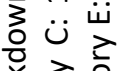

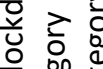

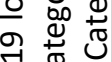

字芒芒

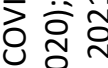

돈ㄷำ

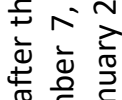

त ह $\frac{5}{0}$

क

s.

ปั

凹

岂㐫过

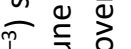

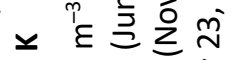

它

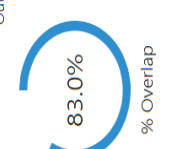

这总

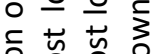

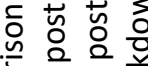

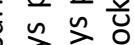

$\frac{\pi}{0} \frac{\pi}{0}$

0 บ

ㅎํㄴ กิ

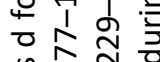

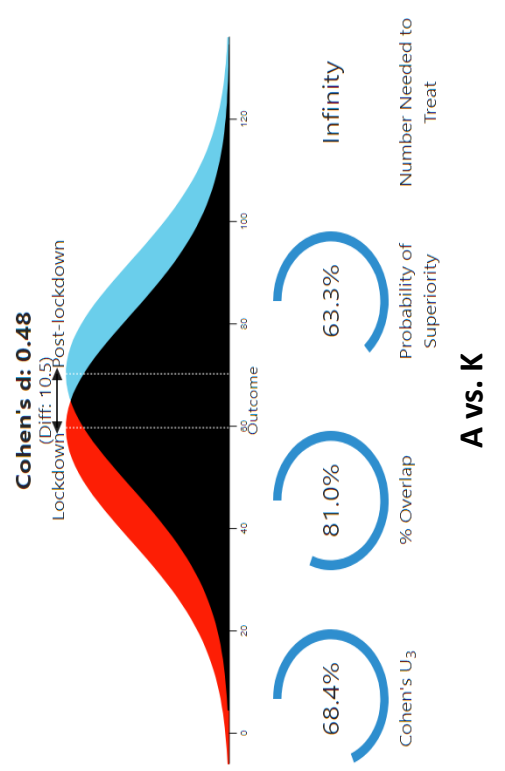

$\dddot{c} \ddot{\theta} \ddot{0}$

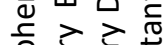

उั

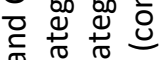

인

言䒾

๘

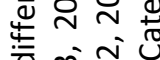

$\sim \stackrel{\sim}{N}$

ทे

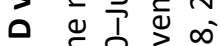

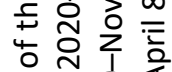

ठ कंत्र

ๆ

蛋

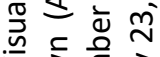

$>\sum_{0} \varepsilon^{2}$

× 응

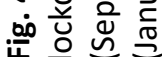


Additionally, there was a $75.1 \%$ probability that a random AQI selected from Category D would be higher than an AQI selected from Category K (lockdown period). Lastly, about $63.2 \%$ of daily $A Q I$ for both categories $D$ and $K$ were similar. On the other hand, the least mean difference noted in B vs. $K$ also relates that only $63 \%$ of the daily AQI between June 24, 2020 to September 7, 2020 (Category B) was above the average AQI of the lockdown period. Furthermore, the probability that a random $A Q I$ selected from Category $B$ would be higher than a selected from Category $K$ was only 59.3\%; while both Category B and $\mathrm{K}$ had a whopping $86.6 \%$ of daily AQI that were similar. The same explanation goes for other plots in the graph. Visualization plots for individual air pollutants (that were positive and statistically significant) are given as supplementary material (Fig. S1).

\section{DISCUSSION}

From the descriptive summary, the following vital characteristics were observed about the quality of air in Wuhan city during and after the lockdown. Firstly, although AQI increased after the lockdown, the overall air quality in Wuhan during and after the lockdown was rated "good", based on the average AQI estimated (Tables 1 and 3). This air quality is generally acceptable; however, the exact $A Q I$ and its corresponding concentration level for some air pollutants (such as $\mathrm{PM}_{2.5}$ ) need to be keenly examined and understood. Because the fact that the description of AQI relies on ranges does not mean that an AQI of 59.7 (lockdown) and 99.8 (Category D) have the same concentration levels for air pollutants. Therefore, depending on the corresponding concentration level for some air pollutants, the air quality of "good" rating may still present a moderate health concern for a small number of people who are very sensitive to air pollution. In such instances, individuals with respiratory or heart disease are cautioned to limit prolonged outdoor exertion (Nikzad et al., 2012). Regarding particulate pollutants, both noted an increase after the lockdown; although it was not immediate. $\mathrm{PM}_{10}$ had a higher concentration than $\mathrm{PM}_{2.5}$ during the lockdown. However, $\mathrm{PM}_{2.5}$ concentration was still above China's daily standard limit of $35 \mu \mathrm{g} \mathrm{m}^{-3}$; consequently, making it unsafe for certain individuals. The average concentrations of $\mathrm{PM}_{10}$ during and after the lockdown indicates it maintained light pollution through both periods. Regarding gaseous air pollutants, $\mathrm{O}_{3}$ recorded the highest concentration level during the lockdown; followed by $\mathrm{NO}_{2}, \mathrm{SO}_{2}$, and $\mathrm{CO}$. Nonetheless, their averages were still below China's daily standard limit of $100 \mu \mathrm{g} \mathrm{m}^{-3}, 80 \mu \mathrm{g} \mathrm{m}^{-3}, 50 \mu \mathrm{g} \mathrm{m}^{-3}$, and $4 \mathrm{mg} \mathrm{m}^{-3}$ respectively consequently labeled "good" (Ministry of Environmental Protection, 2012). After the lockdown, $\mathrm{O}_{3}$ and $\mathrm{NO}_{2}$ noted an immediate increase in concentration levels; which remained consistent for $\mathrm{NO}_{2}$ (concentration never decreased below the record of the lockdown), resulting in a shift from good to light pollution for $\mathrm{NO}_{2}$ pollution.

It is important to note that air pollutants that recorded high concentrations during the COVID-19 lockdown do not directly imply that their emissions were solely related to activities or peculiar sources of the lockdown. This is because air pollutants (especially particulate matter) stay several days to weeks in the atmosphere (Li et al., 2018). Consequently, the usual air quality of the city also played a role in determining the air quality observed during the lockdown. In our previous study, we compared air quality before the COVID-19 outbreak, to air quality during the initial phase of the outbreak/lockdown period. Analysis from that study revealed that concentrations for all air pollutants except CO were higher a few months (1-3 months) prior to the lockdown than concentrations during the lockdown (Ethan et al., 2021). Additionally, the Chinese New Year festivities (officially celebrated at the end of January/start of February) have been noted to affect air quality adversely. The use of firecrackers and fireworks during that period has been established to increase air pollution; with effects that last for several weeks after (Ye et al., 2016). Therefore, seemingly high concentrations of certain air pollutants during the lockdown do not seem illogical. Given the insights generated from our previous study, this study explores if the conclusion has gotten (the lockdown curtailed emissions of air pollutants) can be further supported by observing air quality after the lockdown. This study statistically deduced if there was a significant increase in air pollution after the lockdown.

As established in our previous study, it is important to exercise caution in interpreting these results; and examine the usual concentration levels of air pollutants at particular times of the year. For example, ozone levels are generally low during cold weather and high during hot weather. 
Therefore, since April to September generally has high ozone concentrations, a difference between concentration levels during the lockdown and these months (after the lockdown) would be expected. Therefore, we may consider a real difference in ozone concentration during the lockdown (January 23-April 8, 2020), when compared to the concentration level at the same period of the following year (January 23-April 8, 2021). This is because both times observe the same climatic features (i.e., high wind speed, low relative humidity, low temperature, high atmospheric pressure); hence, any difference observed is void of time/season bias. In this regard, ozone concentrations in the matching months were different (however, not statistically significant) (Fig. 3). A similar logic is followed for particulate matter, which is low in the summer and high in the winter. As a result, concentrating on the comparison of matching months provides an easy but precise assessment of any differences found. However, if air pollutants concentrations that should have been certainly low during the lockdown exceeded the concentration of the succeeding months (particularly for months with a high concentration level), this suggests that air pollution was unusually high during the lockdown. In this regard, no air pollutant was noted

From the independent $t$-test analyses, a positive mean difference indicates the $A Q I$ or air pollution concentration during the lockdown was low and increased after that. $\mathrm{AQI}, \mathrm{NO}_{2}$, and $\mathrm{O}_{3}$ noted positive mean differences for comparison during the lockdown with Category A (April 9, 2020-June 23, 2020) and B (June 24, 2020-September 7, 2020); for comparison with Category C (September 8, 2020-November 22, 2020), only $\mathrm{PM}_{2.5}$ and $\mathrm{CO}$ did not observe positive mean differences; for comparison with Category $\mathrm{D}$ (November 23, 2020-January 22, 2021), only $\mathrm{O}_{3}$ did not note a positive mean difference; while for comparison with Category E (January 23, 2021April 8, 2021), AQI, $\mathrm{PM}_{2.5}, \mathrm{PM}_{10}$, and $\mathrm{NO}_{2}$ noted positive mean differences (Table 3). However, these are only statistically important if the estimates are statistically significant $(p<0.05)$.

For AQI, a statistically significant difference was noted for only comparison D vs. K (229-289 days post lockdown vs. lockdown). Although the mean difference (40.1) seems very large, the actual effect size (0.394) indicates the difference between overall air quality during the lockdown and air quality roughly eight to eleven months after, was medium. Based on Cohen's $U_{3}$ from the $D$ vs. $\mathrm{K}$ plot (Fig. 4), an increase in daily $A Q \mathrm{I}$ six to nine months after the lockdown resulted in approximately 51 days with $A Q I$ higher than the average $A Q I$ during the lockdown. This increase can be largely attributed to the resumption of regular anthropogenic activities in the city. Residents of Wuhan attested to the immediate take-off of several daily activities after the lockdown; most notable, was the use of private vehicles and other forms of public transportation. Consequently, the rise in air pollution was inevitable.

The adverse effect of the rapid return to the use of vehicles is evident from the results generated in this study. Of all air pollutants, $\mathrm{NO}_{2}$ (a major indicator of traffic pollution) was the only air pollutant with immediate and consistent increase after the lockdown; its average concentrations for all periods after the lockdown did not decrease below concentrations during the lockdown. All comparisons except $\mathrm{B}$ vs. $\mathrm{K}$ show $\mathrm{NO}_{2}$ significantly $(p<0.05)$ increased after the lockdown. Based on the effect sizes estimated $(0.245,0.367,0.456,0.447,0.486)$, the difference in $\mathrm{NO}_{2}$ pollution during and after the lockdown, ranged between medium to large. To buttress the point of $\mathrm{NO}_{2}$ increase after the lockdown, Cohen's $\mathrm{U}_{3}(82.8 \%)$ for plot $\mathrm{NO}_{2}-\mathrm{A}$ vs. $\mathrm{K}$ (Fig. S1) deduced that 63 days out of the first 76 days observed after the lockdown recorded concentrations that were higher than the average $\mathrm{NO}_{2}$ concentration during the lockdown. While 69 days out of the 76 days of Category E (January 23-April 8, 2021) also recorded concentrations that were higher than the average $\mathrm{NO}_{2}$ concentration during the lockdown. A similar occurrence was noted after the 2008 Beijing Olympics; air quality worsened, after experiencing a short improvement as a result of the imposed restrictions courtesy of the Olympics (Cao et al., 2013).

Other than transportation-related activities, the resumption of heavy industrial activities brought about an increase in particulate matter pollution after the lockdown. However, this increase only came about eight months after the lockdown (Category D); rather a decrease in particulate pollution was noted for the first seven months after the lockdown (Table 1). This is somewhat understandable and expected, given that the typical trend of particulate pollution dictates a decrease during warmer months and an increase in colder months (Fig. 3). This is because the combustion of coals and fossils (for heating purposes) during cold periods contributes significantly to particulate matter pollution. Winter heating in most Chinese cities starts between November $10^{\text {th }}-15^{\text {th }}$ and ends between March $10^{\text {th }}-15^{\text {th }}$ yearly (Halton, 2010); hence, most parts 
of lockdown (January 23-April 8, 2020) fell within the heating months, consequently, resulting in high particulate pollution. To further emphasize the adverse effects of heating on particulate pollution, our results show that the immediate months succeeding the lockdown, Category A-C (mid-April to early November 2020), which noted particulate concentration lower than that of the lockdown, are warm months without heating. While the only periods post-lockdown with higher concentration are Category D and E (end of November 2020 to early April 2021), months covering the span of winter heating. It is vital to note that though the lockdown period and matching months in 2021 both noted high particulate matter pollution, concentrations in 2021 were slightly higher. This can be attributed to the fact that other than heating, there were other major sources for particles emission in early 2021 that were not present in early 2020 (courtesy of the lockdown) (IQAir, 2021; Sulaymon et al., 2021).

For $\mathrm{SO}_{2}$ and $\mathrm{CO}$, statistically significant increases in concentration levels were only noted about eight months post lockdown (Category D). The effect sizes ( 0.103 and 0.282 ) suggest an increase in $\mathrm{CO}$ and $\mathrm{SO}_{2}$ concentrations post lockdown was small and medium respectively (Table 3 ). The percentage of overlap noted in plots $\mathrm{CO}$ - D vs. $\mathrm{K}$ and $\mathrm{SO}_{2}$ - D vs. $\mathrm{K}$ (Fig. S1), $91.4 \%$ and $74.6 \%$ respectively also indicate concentrations during and post lockdown were not largely different.

As stated above, ozone noted an increase (of 36\%) immediately after the lockdown. Though still unhealthy, this was expected, given that warmer months typically feature high concentrations of ozone. A look at the matching months (lockdown and Category E), shows that concentrations during the lockdown were higher than concentrations one year after; the corresponding effect size $(0.455)$ suggests the difference was medium-scaled. However, this was not statistically. The only statistically significant comparison for ozone was B vs. K (June 24, 2020-September 7, 2020, and January 23, 2021-April 8, 2021). The corresponding visualization (Fig. S1) indicates approximately 59 days between June to September had higher concentrations than average ozone during the lockdown.

Overall, the following changes in air quality were noted. The concentration levels for indicators of traffic-related air pollution $\left(\mathrm{NO}_{2}\right.$ and $\mathrm{CO}$ ) increased post lockdown. $\mathrm{NO}_{2}$ in particular noted a tremendous increase; this owes to the fact that the use of vehicles was one of the very few activities that instantly resumed to full capacity immediately after the lockdown. Several local blogs reported, "After the Chinese government lifted the 76-day lockdown on Wuhan on Wednesday, Chinese social media platforms were quickly filled with videos capturing snarled traffic across the city" (DW.Com, 2020). At its highest average concentration, one year after the lockdown, $\mathrm{NO}_{2}$ noted a $162 \%$ increase in concentration from the lockdown period. This comes with several adverse effects on air quality and most importantly on human health. To mention a few, the mucous membranes of the eyes, nose, throat and respiratory system can be irritated by nitrogen dioxide. Low levels of nitrogen dioxide can trigger bronchial allergies and exacerbate asthmatic patients' allergic reactivity to allergens. Furthermore, nitrogen dioxide can exacerbate the symptoms of people with chronic respiratory illnesses, and long-term exposure to nitrogen dioxide can deteriorate lung function and impair the respiratory system's ability to fight disease (IQAir, 2021; Samoli et al., 2006). Precisely, a study carried out in Wuhan revealed exposure to $\mathrm{NO}_{2}$ significantly increased the risk of influenza (Meng et al., 2020); another showed $\mathrm{NO}_{2}$ was significantly associated with a higher risk of developing mumps (Hao et al., 2019) and another suggested $\mathrm{NO}_{2}$ was significantly associated with chronic obstructive pulmonary disease (COPD) mortality in older adults (Yan et al., 2021).

During the lockdown, Lian et al noted a 3.9\% reduction in $\mathrm{SO}_{2}$ concentration when compared to the previous year (2019) (Lian et al., 2020). This eventually changed about eight months after the lockdown, given that $\mathrm{SO}_{2}$ noted a $33 \%$ increase in concentration. As an indicator of industrial pollution $\left(\mathrm{SO}_{2}\right)$, this increase means residents of industrial areas would once again be heavily challenged with wheezing, chest tightness, shortness of breath, and other respiratory and cardiovascular conditions. Similar to $\mathrm{NO}_{2}$, exposure to $\mathrm{SO}_{2}$ increase the risk of COPD mortality in older adults (Yan et al., 2021).

Although particulate pollution noted some decrease after the lockdown, its concentrations remained at unhealthy levels. Some publications suggest the lowest concentration level at which $\mathrm{PM}_{2.5}$-related deleterious effects begin to show is $3-5 \mu \mathrm{g} \mathrm{m}^{-3}$. Particulates can infiltrate the lungs, tissues, and other organs at or beyond these levels, producing a variety of health problems (Ethan et al., 2020). In Wuhan, some studies have reported the effect of particulate matter on the public's 
health. Yao et al revealed a higher case fatality rate (CFR) of COVID-19 was linked with increasing concentrations of particulate matter (Yao et al., 2020); Wang et al. (2020) reported particulate matter pollution contributed to increasing cardiovascular hospitalization, with an economic cost of almost 30 million RMB (ren mi bi) between 1 January 2015 to 31 December 2017; and Ren et al. (2021) also reported $\mathrm{PM}_{2.5}$ was associated with an increased risk of cardiorespiratory hospital admission in Wuhan.

Regarding ozone, its negative health effects range from minor respiratory problems to cardiovascular diseases to chronic illnesses. Its severe effects now spread beyond aged individuals. A recent study indicated that maternal exposure to $\mathrm{O}_{3}$ in $1 \mu \mathrm{g} \mathrm{m}^{-3}$ level increment was positively associated with newborn congenital hypothyroidism (Qi et al., 2021). Carbon monoxide was posing some major health threats to the public. Depending on the length of exposure and the concentration inhaled, it reduces red blood cell oxygen-carrying capacity. At low levels, the average person experiences headaches, dizziness, and weariness. It can induce impaired vision, loss of coordination, and even death when inhaled in high concentrations (IQAir, 2021).

Other than the changes in air quality, an important observation revealed via the result was the trade-off between $\mathrm{PM}_{2.5}$ and ozone. The distinct decrease in $\mathrm{PM}_{2.5}$ and increase in ozone is a phenomenon that has been noted over the last few years in China. According to Ma et al. (2021), the most important causes driving such a large increase in surface ozone include anthropogenic emission control techniques, changes in aerosol concentrations, and aerosol optical characteristics including single-scattering albedo (SSA). Since ozone is created in the presence of solar radiation by a sequence of photochemical processes that include nitrogen oxides $\left(\mathrm{NO}_{\mathrm{x}}=\mathrm{NO}+\mathrm{NO}_{2}\right)$ and volatile organic compounds (VOCs), $\mathrm{O}_{3}$ levels in the atmosphere are greatly influenced by its precursors' emissions, solar radiation, and other physical processes such as regional and vertical motion. As a result of China's fast industrialization and urbanization, anthropogenic emissions of $\mathrm{NO}_{\mathrm{x}}$ and VOCs, (key precursors of ozone production), have increased dramatically in recent decades. For example, from 1996 to 2011, tropospheric columns of $\mathrm{NO}_{2}\left(\mathrm{TCNO}_{2}\right)$, a measure of anthropogenic $\mathrm{NO}_{\mathrm{x}}$ emission concentration, increased by $307 \%$ in Beijing, resulting in a substantial ozone rise. According to the Multi-resolution Emission Inventory in China (MEIC), anthropogenic emissions of $\mathrm{PM}_{2.5}$ reduced by roughly $60 \%, \mathrm{NO}_{x}$ emissions lowered by $21 \%$, and decrease in other air pollutants such as $\mathrm{SO}_{2}$ were also observed, but not for VOCs, which increased by $2 \%$ between 2013 and 2017. In addition to increased VOC emission, the reduction of particulate matter also contributes to increased ozone concentration. This is because fewer particulates in the atmosphere result in a reduction of aerosol optical depth (AOD). AOD is a measure of extinction of solar beam by aerosols such as e.g., dust, particles, and haze; it is used as a proxy of representing the severity of fine particulate-matter pollution or aerosol mass concentrations. A high aerosol concentration means a high measure of scattered radiation, and a low aerosol concentration, a low measure of scattered radiation. Therefore, with fewer aerosols (particulates), there is more UV radiation reaching the troposphere, leading to a higher photolysis rate of $\mathrm{NO}_{2}$ (a vital parameter in $\mathrm{O}_{3}$ formation).

\section{CONCLUSION}

In summary, daily anthropogenic activities were established as a major contributor to air pollution in Wuhan. Given that a lower AQI (59.7) was observed when daily human activities were less, and higher AQI (between 70.2-99.8) when daily activities had increased. Overall, the air quality in Wuhan was not greatly degraded after the lockdown. Nonetheless, caution should be observed for some sensitive groups, as several health risks still exist. Regarding individual air pollutants, traffic-related pollution noted the most immense changes (medium to large), as revealed by the effect sizes $(0.245,0.367,0.456,0.447,0.486)$ of $\mathrm{NO}_{2}$. Particulate matter also noted some changes (decreased concentration during the initial months after the lockdown); however, its levels were mostly still above the WHO standard limit. Additionally, observation of matching months showed that 48 out of 76 days (January 23-April 8, 2021) had higher fine particulate concentration than during the lockdown; while the coarse particulate matter was noted 54 days of higher concentration than the lockdown. These indicate that particulate emission level one-year post lockdown remains a challenge as it was prior to the lockdown. In contrast to 
other air pollutants, ozone noted higher concentrations $\left(86.0 \mu \mathrm{g} \mathrm{m}^{-3}\right)$ during the lockdown compared to matching months in 2021. The exact reason or source of emission was not deduced. However, the reduction of particulate matter emissions has the propensity to increase $\mathrm{O}_{3}$ levels since it enhances the photolysis rates of $\mathrm{NO}_{2}$. Also, an increase in photochemical pollution and the emission of volatile organic compounds (VOCs) during the lockdown could be a contributing factor for the high ozone concentration observed. Holistically, in as much as the lockdown noted relatively lower concentrations for some air pollutants, for several reasons, economic and otherwise, it is not the best regulatory means for curtailing emission. More reasonable, yet stringent control measures are needed to achieve lower emissions.

\section{ADDITIONAL INFORMATION}

\section{Strengths and Limitations}

The strengths and limitations of this study are as follows. This is original research highlighting the impact of man's daily activities on air quality. Precisely, the study describes the effect of some routines (such as the use of vehicles and winter heating) on air quality. The study creates a window of opportunities for different related studies (to understand the health risk associated with air quality during and post lockdown). The study is limited in a few aspects. Firstly, the analysis did not describe the effects or influence of meteorological parameters (temperature, relative humidity, wind speed) on the change in air quality during and post lockdown. Secondly, the analysis only describes the quality of air in Wuhan; the data were not correlated with health data to assess exposure risk.

\section{Competing Interests}

The authors declare no competing interests.

\section{Funding}

This research did not receive grants from any funding agencies in the public, commercial, or non-profit sectors.

\section{Authors Contribution}

Crystal Jane Ethan conceived the idea. Yan Yu provided the data. Crystal Jane Ethan and Kingsley Katleho Mokoena analyzed the data and wrote the manuscript. All authors read and approved the manuscript.

\section{SUPPLEMENTARY MATERIAL}

Supplementary material for this article can be found in the online version at https://doi. org/10.4209/aaqr.210282

\section{REFERENCES}

Cao, H., Hidemichi, F., Shunsuke, M. (2013). Environmental impact of the 2008 Beijing Olympic Games. Economics Discussion Papers, No 2013-30, Kiel Institute for the World Economy. http://www.economics-ejournal.org/economics/discussionpapers/2013-30 (accessed 21 September 2021).

Chan, J.F.W., Yuan, S., Kok, K.H., To, K.K.W., Chu, H. (2020). A familial cluster of pneumonia associated with the 2019 novel coronavirus indicating person-to-person transmission: A study of a family cluster. Lancet 395, 514-523. https://doi.org/10.1016/S0140-6736(20)30154-9

Chen, J., Zhang, Y., Zhu, S., Liu, L. (2021). Does COVID-19 Affect the behavior of buying fresh food? Evidence from Wuhan, China. Int. J. Environ. Res. Pub. Health 18, 4469. https://doi.org/10.33 90/ijerph18094469

Cohen, J. (1998). Statistical Power Analysis for the Behavioral Sciences, 2nd ed. Lawrence 
Erlbaum Associates: Hillsdale, NJ, USA, pp. 1-567.

Durlak, J. (2009). How to select, calculate, and interpret effect sizes. J. Pediatr. Psychol. 34, 917928. https://doi.org/10.1093/jpepsy/jsp004

DW.Com. (2020). What is life like in post-lockdown Wuhan? https://www.dw.com/en/what-islife-like-in-post-lockdown-wuhan/a-53066534 (accessed 25 September 2021).

Ethan, C.J., Mokoena, K.K., Yu, Y., Shale, K., Fan, Y., Rong, J., Liu, F. (2020). Association between $\mathrm{PM}_{2.5}$ and mortality of stomach and colorectal cancer in Xi'an: A time-series study. Environ. Sci. Pollut. Res. Int. 27, 22353-22363. https://doi.org/10.1007/s11356-020-08628-0

Ethan, C.J., Mokoena, K.K., Yu, Y. (2021). Air pollution status in 10 mega-cities in China during the initial phase of the COVID-19 outbreak. Int. J. Environ. Res. Pub. Health 18, 3172. https://doi.org/10.3390/ijerph18063172

Halton, C. (2010). CBS News. Chinese Freeze Before Gov't Turns on the Heat. https://www.cbsnews.com/news/chinese-freeze-before-govt-turns-on-the-heat/ (accessed 30 September 2021)

Hao. J., Yang, Z., Huang. S., Yang, W., Zhu, Z., Tian. L., Lu, Y., Xiang, H., Liu, S. (2019). The association between short-term exposure to ambient air pollution and the incidence of mumps in Wuhan, China: A time-series study. Environ. Res. 177, 108660. https://doi.org/10.1016/j.en vres.2019.108660

IQAir (2021). Air quality in Wuhan. https://www.iqair.com/china/hubei/wuhan (accessed 28 September 2021).

Landau, S., Everitt, B.S. (2004). A Handbook of Statistical Analyses Using SPSS. Chapman \& Hall/CRC: Boca Raton, FL, USA, pp. 36-69.

Li, B., Li, S., Xiao, C., Zhang, C., Chen, J., Lin, H., Du, Y., Liu, M. (2018). Time series analysis of deaths of residents with malignant granules in Shenyang, China. Oncol Lett. 16, 4507-4511. https://doi.org/10.3892/ol.2018.9186

Lian, X., Huang, J., Huang, R., Liu, C., Wang, L., Zhang, T. (2020). Impact of city lockdown on the air quality of COVID-19-hit of Wuhan city. Sci Total Environ. 742, 140556. https://doi.org/10.10 16/j.scitotenv.2020.140556

Ma, X., Huang, J., Huang, J., Huang, J., Zhao, T., Liu, C., Zhao, K., Xing, J., Xiao, W. (2021). Rapid increase in summer surface ozone over the North China Plain during 2013-2019: A side effect of particulate matter reduction control? Atmos. Chem. Phys. 21, 1-16. https://doi.org/10.519 4/acp-21-1-2021

Magnusson, K. (2014). Interpreting Cohen's D effect size: An interactive visualization (Version 2.1.1). R Psychologist. https://rpsychologist.com/d3/cohend/ (accessed on 27 September 2021).

Meng, Y., Lu, Y., Xiang, H., Liu, S. (2020). Short-term effects of ambient air pollution on the incidence of influenza in Wuhan, China: A time-series analysis. Environ. Res. 192, 110327. https://doi.org/10.1016/j.envres.2020.110327

Ministry of Environmental Protection (2012). China: Air quality standards (GB 3095-2012). https://www.transportpolicy.net/standard/china-air-quality-standards/ (accessed 28 September 2021).

Mokoena, K.K., Ethan, C.J., Yu, Y., Quachie, A.T. (2020). Interaction effects of air pollution and climatic factors on circulatory and respiratory mortality in Xi'an, China between 2014 and 2016. Int. J. Environ. Res. Pub. Health 17, 9027. https://doi.org/10.3390/ijerph17239027

Nikzad, N., Verma, N., Ziftci, C., Bales, E., Quick, N., Zappi, P., Patrick, K., Dasgupta, S., Krueger, I., Rosing T.Š., Griswold, W.G. (2012). CitiSense: Adaptive services for community-driven behavioral and environmental monitoring to induce change. https://www.researchgate.net/p ublication/262337743_CitiSense_Adaptive_Services_for_Community-driven_Behavioral_and _Environmental_Monitoring_to_Induce_Change

Pérez-Vicente, S., Expósito-Ruiz, M. (2009). Descriptive statistics. Br Dent J. 9, 37, 314-320.

Piovesana, A., Senior, G. (2016). How big is small: Sample size and skewness. Assessment 25, 793800. https://doi.org/10.1177/1073191116669784

Qi, C., Shang, L., Yang, W., Huang, L., Yang, L., Xin, J., Wang, S., Yue, J., Zeng, L., Chung, M.C. (2021). Maternal exposure to $\mathrm{O}_{3}$ and $\mathrm{NO}_{2}$ may increase the risk of newborn congenital hypothyroidism: A national data-based analysis in China. Environ. Sci. Pollut. Res. Int. 28, 34621-34629. https://doi.org/10.1007/s11356-021-13083-6 
Ren, Z., Liu, X., Liu, T., Chen, D., Jiao, K., Wang, X., Suo, J., Yang, H., Liao, J., Ma, L. (2021). Effect of ambient fine particulates $\left(\mathrm{PM}_{2.5}\right)$ on hospital admissions for respiratory and cardiovascular diseases in Wuhan, China. Respir. Res. 22, 128. https://doi.org/10.1186/s12931-021-01731-x

Rstats Institute Missouri (2012). Tables and Calculators. https://www.missouristate.edu/rst ats/Tables-and-Calculators.htm (accessed 14 April 2020)

Samoli, E., Aga, E., Touloumi, G., Nisiotis, K., Forsberg, B., Lefranc, A., Pekkanen, J., Wojtyniak, B., Schindler, C., Niciu, E., Brunstein, R., Fikfak, M.D., Schwartz, J., Katsouyanni, K. (2006). Shortterm effects of nitrogen dioxide on mortality: An analysis within the APHEA project. Eur. Respir. J. 27, 1129-1138. https://doi.org/10.1183/09031936.06.00143905

Sawilowsky, S. (2009). New effect size rules of thumb. J. Mod. Appl. Stat. Meth. 8, 467-474. https://doi.org/10.22237/jmasm/1257035100

Sulaymon, I.D., Zhang, Y., Hopke, P.K., Zhang, Y., Hua, J., Mei, X. (2021). COVID-19 pandemic in Wuhan: Ambient air quality and the relationships between criteria air pollutants and meteorological variables before, during, and after lockdown. Atmos. Res. 250, 105362. https://doi.org/10.1016/j.atmosres.2020.105362

The Analysis Factor (2021). When unequal sample sizes are and are not a problem in ANOVA. https://www.theanalysisfactor.com/when-unequal-sample-sizes-are-and-are-not-a-problemin-anova/ (accessed 25 September 2021).

Wang, P., Chen, K., Zhu, S., Wang, P., Zhang, H. (2020). Severe air pollution events not avoided by reduced anthropogenic activities during COVID-19 outbreak. Resour. Conserv. Recycl. 158, 104814. https://doi.org/10.1016/j.resconrec.2020.104814

Wang, X., Yu, C., Zhang, Y., Shi, F., Meng, R., Yu, Y. (2020). Attributable risk and economic cost of cardiovascular hospital admissions due to ambient particulate matter in Wuhan, China. Int. J. Environ. Res. Public Health 17, 5453. https://doi.org/10.3390/ijerph17155453

Wen, Y. (2016). China's rapid rise: From backward agrarian society to industrial powerhouse in just 35 years. 2016. Federal Reserve Bank of St. Louis. https://www.stlouisfed.org/publications/ regional-economist/april-2016/chinas-rapid-rise-from-backward-agrarian-society-to-industrialpowerhouse-in-just-35-years (accessed 08 October 2021)

World Air Quality Project Team (2021). Air pollution in China: Real-time air quality index visual map. https://aqicn.org/map/china/ (accessed 28 September 2021)

Yan, Y., She, L., Guo, Y., Zhao, Y., Zhang, P., Xiang, B., Zeng, J., Yang, M., Wang, L. (2021). Association between ambient air pollution and mortality from chronic obstructive pulmonary disease in Wuhan, China: A population-based time-series study. Environ. Sci. Pollut. Res. Int. 1, 1-9. https://doi.org/10.1007/s11356-021-13180-6

Yao, Y., Pan, J., Liu, Z., Meng, X., Wang, W., Kan, H., Wang, W. (2020). Temporal association between particulate matter pollution and case fatality rate of COVID-19 in Wuhan. Environ. Res. 189, 109941. https://doi.org/10.1016/j.envres.2020.109941

Ye, C., Chen, M. (2016). The impacts of Chinese Nian culture on air pollution. J. Cleaner Prod. 112, 1740-1745. https://doi.org/10.1016/j.jclepro.2015.04.113

Yin, P., Brauer, M., Cohen, A.J., Wang, H., Li, J., Burnett, R.T., Stanaway, J.D., Causey, K., Larson, S., Godwin, W., Frostad, J., Marks, A., Wang, L., Zhou, M., Murray, C.J.L. (2020). The effect of air pollution on deaths, disease burden, and life expectancy across China and its provinces, 1990-2017: An analysis for the Global Burden of Disease Study 2017. Lancet Planet. Heath 4, e386-e398. https://doi.org/10.1016/S2542-5196(20)30161-3 